\title{
DESIGN AND ANALYSIS METHODS FOR COMPOSITE BONDED JOINTS
}

\author{
Przemysław Dobrzański (DD 0000-0003-3054-073X \\ Witold Oleksiak (D) 0000-0003-3485-8956 \\ Łukasiewicz Research Network - Institute of Aviation, Al. Krakowska 110/114, Warsaw 02-256, Poland \\ przemyslaw.dobrzanski@ilot.lukasiewicz.gov.pl, \\ witold.oleksiak@ilot.lukasiewicz.gov.pl
}

\begin{abstract}
A literature review on existing design and analysis methods for composite adhesively bonded joints has been conducted. Methods that might form a basis for development of practical engineering methodology for adhesively bonded joints were selected and described. Starting from the simplest and the fastest analytical methods (closed-form solutions): average shear stress, shear lag model and adhesive beam model through more complex and more time consuming numerical methods supported by finite element analysis: global models, local models, cohesive zone models. Assumptions and applicability of each method was discussed. Simple and fast methods in order to be reliable have to include many conservative assumptions and therefore may lead to over-designed structure (weight penalty). Structural optimization and weight reduction require the usage of more complex and time consuming methods. Therefore, selection of adequate methods should always be balanced against strength, durability, costs and weight.
\end{abstract}

Keywords: composites, adhesives, analytical models, numerical models, stress analysis. Type of the work: Review Paper

\section{INTRODUCTION}

Aircraft structures consist of a multiple elements that need to be jointed together in order to form a load transfer path. There are multiple joint types that are used in airframe construction: mechanically fastened using bolts or rivets, adhesively bonded using a polymeric adhesive, combination of these two, welded, clamped [1, 2]. One of the responds to increasing demand for efficient lightweight structures, especially in aerospace industry, is increasingly use of adhesively bonded joints of composite structures. This kind of joints have been extensively used especially in General Aviation aircrafts. One of the first nearly all composite light aircraft with extensive use of adhesive bonding as a primary method for forming structural joints was Cirrus SR20 (Fig. 1(a)) built and produce by Cirrus Aircraft and certified in 1998 by FAA [3]. First Polish nearly all composite aircraft with extensive use of adhesive bonding was PZL I-23 Manager (Fig. 1 (b)) certified in 2001 by Civil Aviation Authority in Poland and in 2006 by EASA [4]. In the recent years, more and more adhesive bonding have been used in transport category aircrafts. Both Boeing 787 and the Airbus A 350 contain more than 50\% bonded composite structures [5]. 


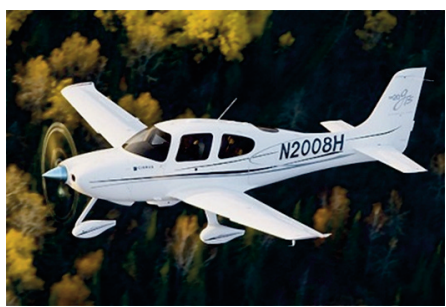

(a) Cirrus SR20

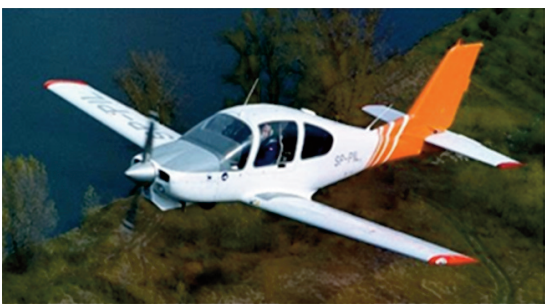

(b) PZL I-23 Manager

Fig. 1. General Aviation nearly all-composite adhesively bonded aircrafts.

Adhesive is defined as a substrate that is capable of strongly and permanently holding two surfaces together [6]. Adhesive bonding is a joining technique in which an adhesive material, placed between the surface of parts being bonded, knowns as a substrates or adherends, solidifies to produce an adhesive bonds $[6,7]$. To avoid confusion, term adherends will be used throughout the article (Fig. 2). The adhesive material adheres to the adherends and transfer force between them.

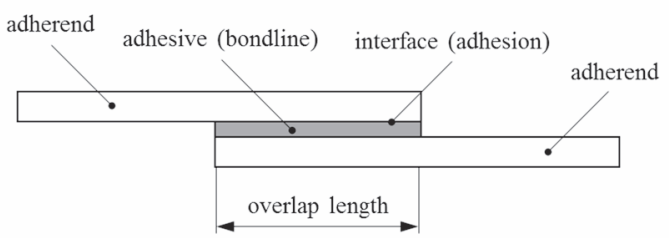

Fig. 2. General bonded joint nomenclature.

Adhesively bonded joints provide many advantages over mechanical fasteners. Large surfaces, dissimilar materials and thin substrates can be joined together, reducing number of parts required and obtaining smooth surface contour (e.g. scarf joint) [1][2, 6]. Adhesive do not damage the adherends and therefore do not introduce stress concentrations and discontinuity of fibers [7, 8]. However, a concentration of load transfer along the bondline edge may exist (this can be managed through configuration changes or local design modifications) [2]. Moreover, the adhesive has a natural tendency to resist crack propagation, and hence provides a significant resistance for fatigue growth from one component to another [2]. These result in one of the main advantage of adhesively bonded joints - excellent fatigue performance [1, 2, 6, 9]. Adhesively bonded joints provide uniform stress distribution along the bonded area (except at edges), higher joint stiffness and load capacity, reducing the weight and the costs [2, 6, 7,9]. Additionally, the operation of bonding two surfaces together will automatically seal the surfaces where the adhesive layer will act as a corrosion barrier between dissimilar materials resulting in excellent corrosion performance $[1,2,9]$.

However, adhesively bonding joints have also several disadvantages. The thickness of the parts that can be joined is limited. Once this thickness limit is achieved the joint becomes both structurally and/or geometrically inefficient $[1,2]$. Inspection of bonded joints is very difficult and even though series of nondestructive techniques are now available, the most reliable methods are destructive one $[1,2,6,9]$. One of the major requirements for durable, high quality bondline, is surface preparation process strictly controled by quality control procedures $[1,2,6,9,10]$. Adhesives and the bondline, due to polymeric nature, are prone to environmental degradation - high temperature and moisture absorption can degrade joint stiffness and strength $[1,2,6,9,10]$. Adhesively bonded joints are the most efficient when they transfer the load through the in-plane shear. Their strength is very sensitive to peel and through 
the thickness stresses, and therefore these stresses should be reduced to minimum by the proper design $[1,2,9]$. Joints with adherends that have different coefficients of thermal expansion, cured in process that requires high temperatures, will results in induced residual thermal stresses within the adhesives [1, 2]. One of the most economical disadvantage of bonded joints is related with curing process. Bonding is usually not instantaneous and curing time might be long. Therefore, bonding process may require costly tooling and facilities $[1,6,9]$. Adhesively bonded joints, once fabricated, cannot be disassembled without damaging the adhesive and/or adherends $[1,2]$.

The bonded joint design and analysis tends to be complex in many cases. There are no simple rules such as in the case of bolts, rivets, or welding, and design engineers still do not trust this technique, especially when it comes to long-term strength. With the use of structural high performance adhesives, new design methods have been developed and require understanding to achieve improvements in structural efficiency. Moreover, implementing this design rules into fabrications process requires special skills that need to be taught and practice constantly $[2,6,9]$.

In order to design durable and efficient adhesively bonded joint, a reliable and fast analysis and failure prediction methods are needed. It is a big challenge because analysis of adhesive bonded joint is very complex task and there is a lot of limitations and uncertainties in what can be predict. Therefore, there is a tendency to use simple design rules, costly experimental trials and testing campaigns, or even additional safety precaution like mechanical fasteners. These result in heavier and more costly components (overdesign structures) [3, 8, 10,11].

Analysis methods are needed to predict the joint strength: determine stress/strain distribution in the adherends and the adhesive and predict probable failure points $[8,10,12]$. Stress/strain distribution can be obtained from two mathematical approaches: analytical methods (closed-form analysis) and numerical methods (i.e. finite element analysis) $[8,12]$. For simple joints and initial analysis the closedform analysis is more appropriate [13]. The more complex joint and the more detailed analysis, the more advanced methods are required. Geometrical features and shapes, nonlinear materials, stress gradients, boundary conditions, etc. result in necessity of using the finite element methods. Finally there is always a question related with failure criterion to be used in the analysis [3, 10, 11].

The objective of this paper is to review existing design and analysis methods, analytical and numerical, available in the literature, that might form a basis of practical engineering methodology for designing adhesively bonded joint for weight efficient structures (easy-to-use methods and tools).

\section{DESIGN AND ANALYSIS METHODS}

\subsection{Types of bonded joints}

There are numerous bonded joint configurations possible. The most common were shown in Fig. 3. Single lap joint (Fig. 3 (a)) is the simplest type and is dedicated primarily for thin adherends with relatively low applied loads. Limitations of single lap joints are caused by the eccentricity in the load path that causes rotational displacement (bending) and therefore increase in peel stresses. This effect can be minimized by using thin adherends with sufficient overlap lengths. Additionally peel stresses can be minimized by tapering adherends edges (Fig. 3 (b)). Simple double lap joint (Fig. 3 (d)) is an improvement over a single lap joint that eliminates load path eccentricity and has twice the overlap surface area. Nevertheless, peel stresses that still exist at the joint ends can be significant. These can be limited (not eliminated) by tapering adherends ends (Fig. 3 (e)). Single strapped joint (Fig. 3 (f)) can be used to join two part in the same plane and therefore eliminate load eccentricity for cases of symmetrical parts. However geometrical eccentricity within the joint still exist and can increase peel stresses at the ends of the joint. This can be reduced by using double strapped joint or double taper strapped joint (Fig. $3(\mathrm{~g}, \mathrm{~h})$ ). From the load capability point of view the next level of the joint is stepped lap (Fig. 3 (i, j). This kind of joint has lower peak shear and 
peel stresses in the bondline and is practical solution for thicker adherends. Improved load capability over stepped joint characterize scarf joint. In theory peak peel stresses in the bondline of stepped joint can be minimized to almost any desired value, but in practice this is limited by overall joint size and manufacturing imperfections. From strength perspective, stepped and scarf joints have the highest possible capability, but from the manufacturing perspective they are much more difficult and expensive to produce than single or double lap joints.

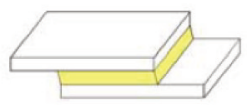

(a) Simple single lap joint

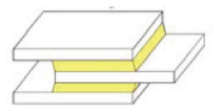

(d) Simple double lap joint

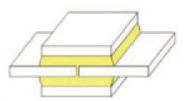

(g) Strapped double joint

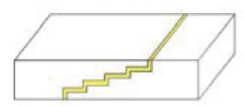

(j) Recessed stepped lap joint

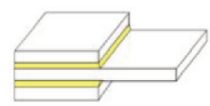

(m) Double sided bonded doublers

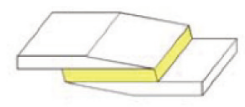

(b) Taper single lap joint

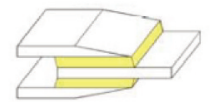

(e) Taper double lap joint

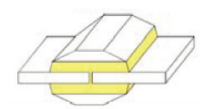

(h) Strapped double taper joint

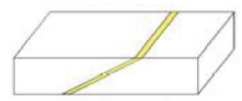

(k) Single taper scarf joint

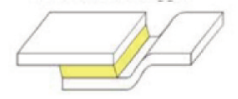

(c) Joggle single lap joint

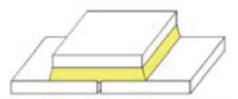

(f) Strapped single joint

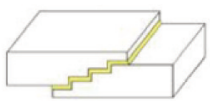

(i) Simple stepped lap joint

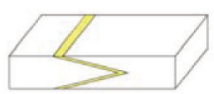

(l) Double taper scarf joint

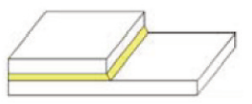

(n) Single sided bonded doublers

Fig. 3. Types for adhesive bonded joint [14].

Examples of structural application of discussed types for adhesive bonded joint were presented below. Fig. 4 presents simple single lap joint used in bonded drive shaft end fitting, and joggle single lap joint used in a large transport aircraft fuselage to bond together two halves of barrel. Typical aft section of small aircraft bonded fuselage was shown in Fig. 6. At least few applications of bonded joints can be noticed. Fuselage halves can be joined using joggled single lap, splice strap single lap or splice strap double lap joints, where all joints assure smooth external surface and therefore better aerodynamics. Repair or reinforcement of the structure is realized by bonded doubler. Typical bonded wing spar construction was shown in Fig. 6. Spar webs are bonded to spar caps creating double lap joint.

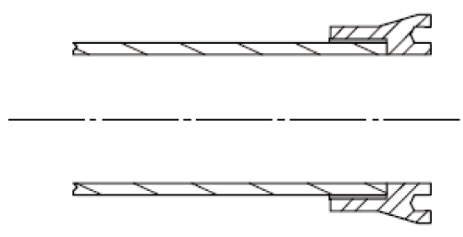

(a) Drive shaft end fitting
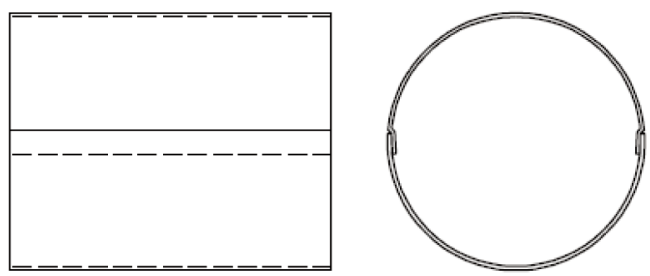

(b) Longitudinal joint 
Fig. 4. Circumferential- and longitudinal-bonded joints [3].

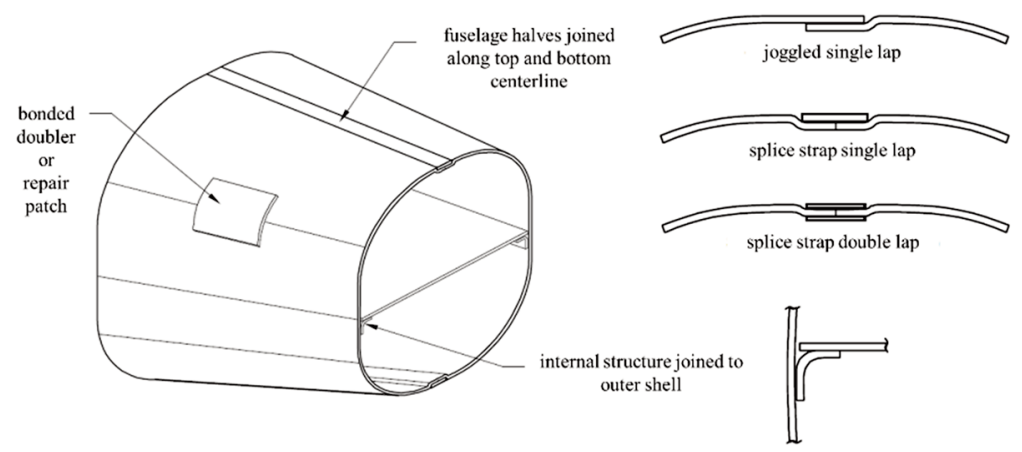

Fig. 5. Typical aft section of small aircraft bonded fuselage [3].

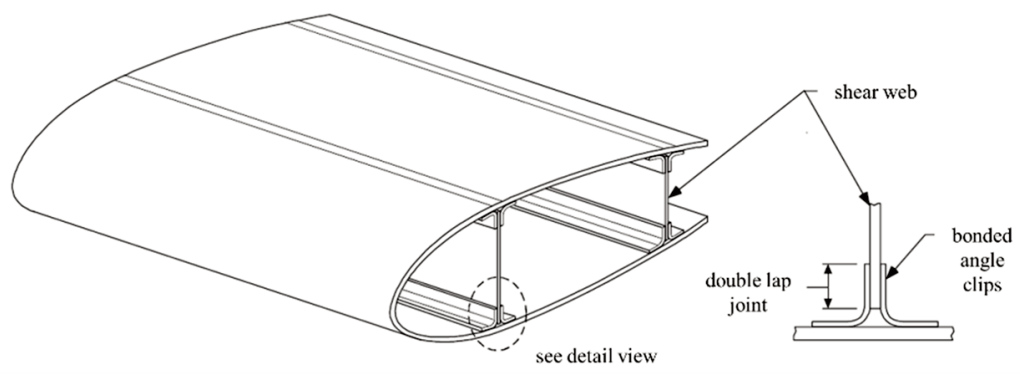

Fig. 6. Generic-bonded wing spar construction [3].

\subsection{Failure modes of bonded joint}

Bonded joint may fail in four ways: adherend failure outside the joint, cohesion failure of the adhesive, adhesion failure (interface failure) and mixed-mode failure. Adherend failure outside the joint (cohesion failure of the adherend) indicates its proper design and therefore is the most desired failure mode for bonded joint (Fig. 7 (a)). However, such case may not always be possible to achieve and is more achievable for metal than for composite adherends. Composite adherends can fail in different way than metals interlaminar shear and delamination are often critical modes (Fig. 7 (b)). Cohesion failure of the adhesive is usually design driven (inadequate overlap, adhesive load capacity, thermal stresses etc.) Adhesive material may fail in shear (Fig. 7 (c)), in tension (peel, Fig. 7 (d)) or in combination of these two (Fig. 7 (g)). This mode is indicated by the presence of a rough layer of adhesive on both the separated adherends (Fig. 8). Adhesion failure along the interface is a manufacturing process driven failure that occurs when proper adhesion is not obtained. This might be caused by surface contamination during manufacturing or when surface preparation process does not assure that durable bonds are produce. Moreover, adhesion failure may occur in-service after interfacial degradation over time. This mode is indicated by the presence of adhesive material on just a single adherend (Fig. 8). This mode cannot be predicted by analytical methods and therefore such methods always assume that it is not critical despite the fact that this can often be critical mode. Mixed-mode failure is another manufacturing process driven failure that is combination of adhesive and cohesive failures. This failure may appear when durable surface preparation process was applied only partially or surface contamination was local. Despite the fact cohesion shear and peel failure (Fig. 7 (c) (d)), and adhesive shear and peel failure (Fig. 7 (e) (f)) were shown below as a separate failure modes, in reality adhesive failure will always result from combination of shear and peel components - peel 
stress can be minimized, but not eliminated.

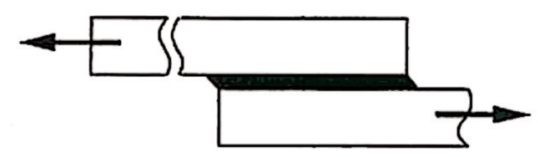

(a) Adherend failure outside the joint

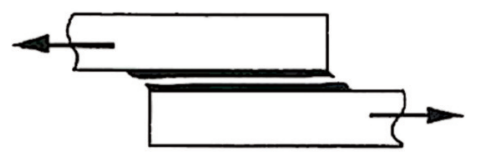

(c) Cohesive shear failure

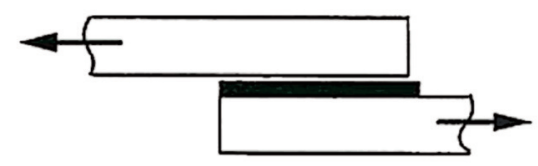

(e) Adhesive shear failure

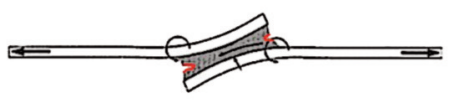

(g) Adhesive combined shear and peel failure

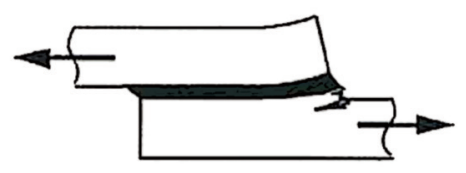

(b) Adherend failure for composites

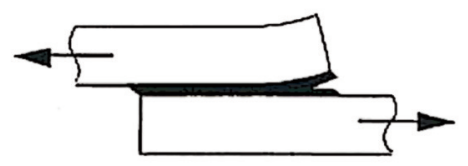

(d) Cohesive peel failure

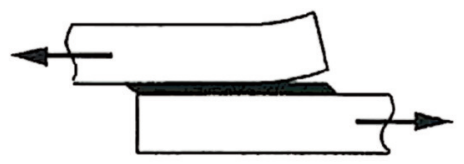

(f) Adhesive peel failure

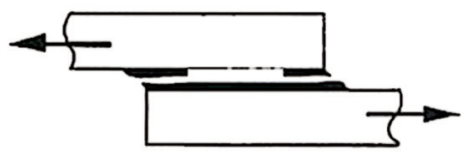

(h) Mixed-mode failure

Fig. 7. Types of bonded joint failure modes [15].
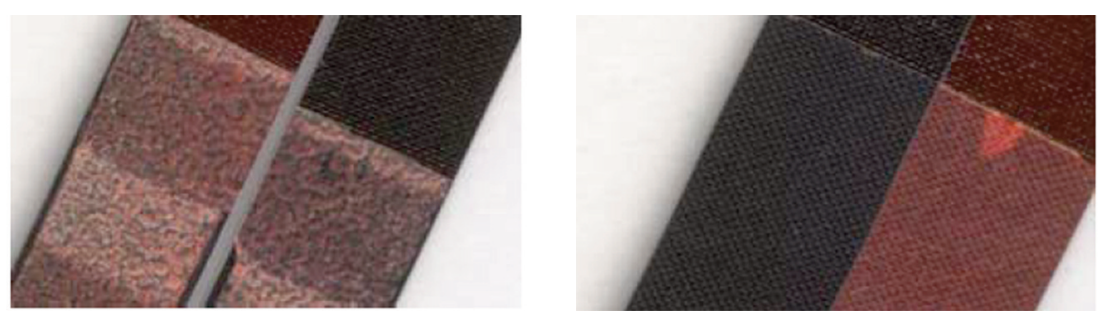

Fig. 8. Cohesive (left) and adhesive (right) failure of bonded joint [16].

\subsection{Design of bonded joint}

Design of bonded joint starts with selection of the most adequate type for given application. Selection should be based on a few factors. First factor is related with required load carrying capability. For cases of relatively thin parts and low loads the simplest joint types (single or double lap joint) might be sufficient. With the increase of parts thickness and load requirements, the more complex joint types should be considered (stepped or scarf joint). Joint capability trends with regards to their types and adherends thicknesses were shown in Fig. 9. Second factor is related with available overlap length. For example stepped and scarf joints, depending on assumed single steps number and their length or scarf angle, might be impossible to implement. Third factor concerns aesthetics and aerodynamics. Multi stepped and scarf joints can produce smoother surfaces and therefore, for external surfaces, assure better aerodynamics. Selection of bonded joint type must always be balanced against complexity of the manufacture. 


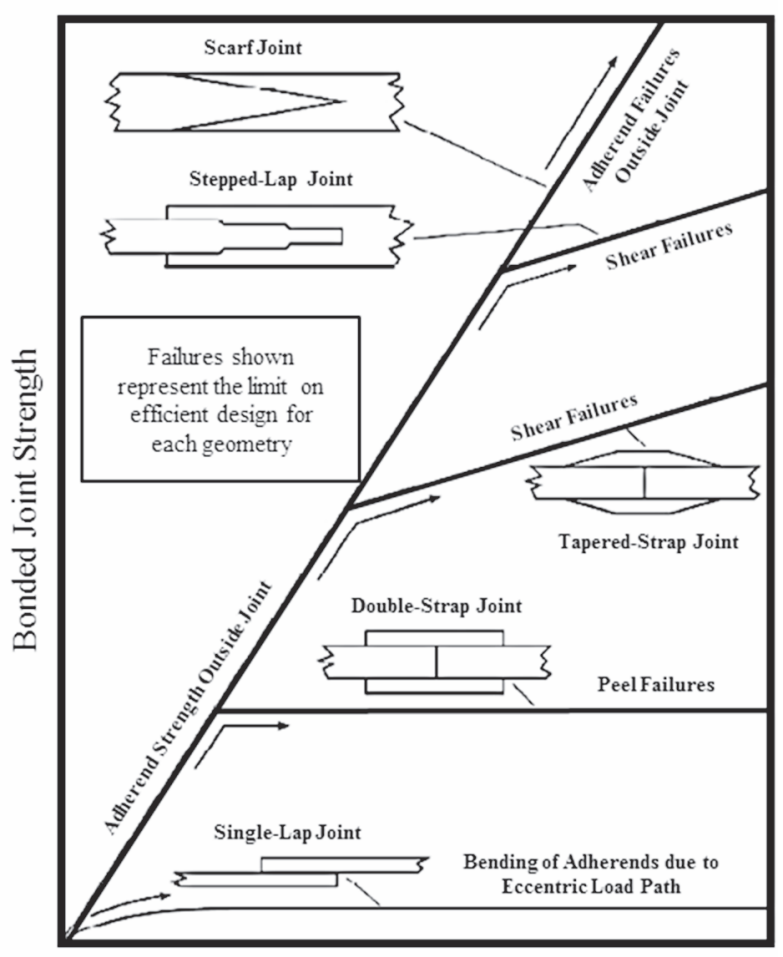

Adherend Thickness

Fig. 9. Bonded joint selection - influence of member size [17].

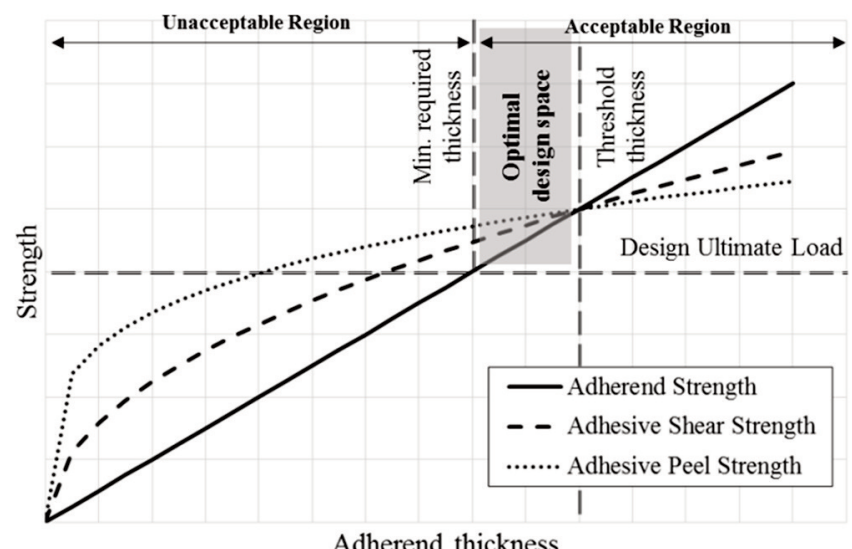

Fig. 10. Adherend and adhesive strength versus adherend thickness.

For selected bonded joint, the required strength of the adherends and adhesive should be assured. In first step adherends and the adhesive strength must be greater than design ultimate load. Adherend and adhesive strength relationship with adherend thickness was shown in Fig. 10. The strength of 
the adherend is linearly dependent upon its thickness, shear strength of the adhesive is square root of thickness of adherend, and peel strength is fourth root of thickness of adherend $[15,18,19]$. It can be noticed that for thin adherends, their strength is lower than adhesive shear and peel strength, and this relation last up to threshold thickness. Thus, the bond will never fail as long as the adherend thickness is lower than threshold thickness. Therefore, the optimal design space for bonded joint will be limited by design ultimate load, minimal required thickness and threshold thickness values as shown in Fig. 10. Nevertheless, such criterion might be very difficult to achieve for composite structures, where interlaminar failures in the composite adherends surface plies are common, especially for pull off and other out-ofplane loading conditions. Therefore, such criterion should be restated to mean precluding the adhesion failure (if the adhesive material is going to fail, it should always be in a cohesive failure mode) [20].

Typical structural adhesive materials exhibit an elastic-elastoplastic behavior. For most modern structural adhesives, majority of the strain energy to failure is due to plastic behavior [21]. When the joint is loaded above the adhesive elastic limit, plastic zones create at the bondline ends. Optimal adhesively bonded joint should have sufficient overlap length that will assure all load carried in the plastic zone, and have large enough elastic zone for fatigue and creep resistance. Example of such optimal scenario was shown in Fig. 11 [15]. There is a certain overlap length over which there is no increase in joint strength, but long overlaps are desirable because they provide high level of damage tolerance to voids and other flaws. Nevertheless, it should always be balanced against strength, durability, costs and weight $[1,15]$.

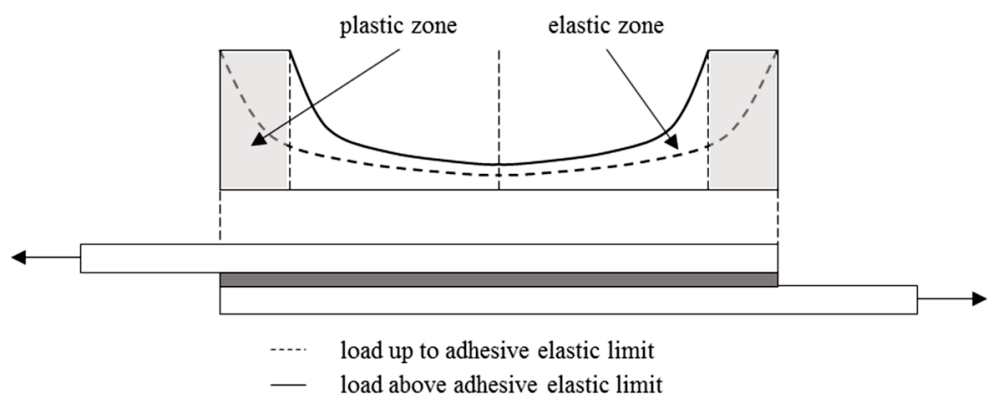

Fig. 11. Elastic-plastic shear stress in adhesive.

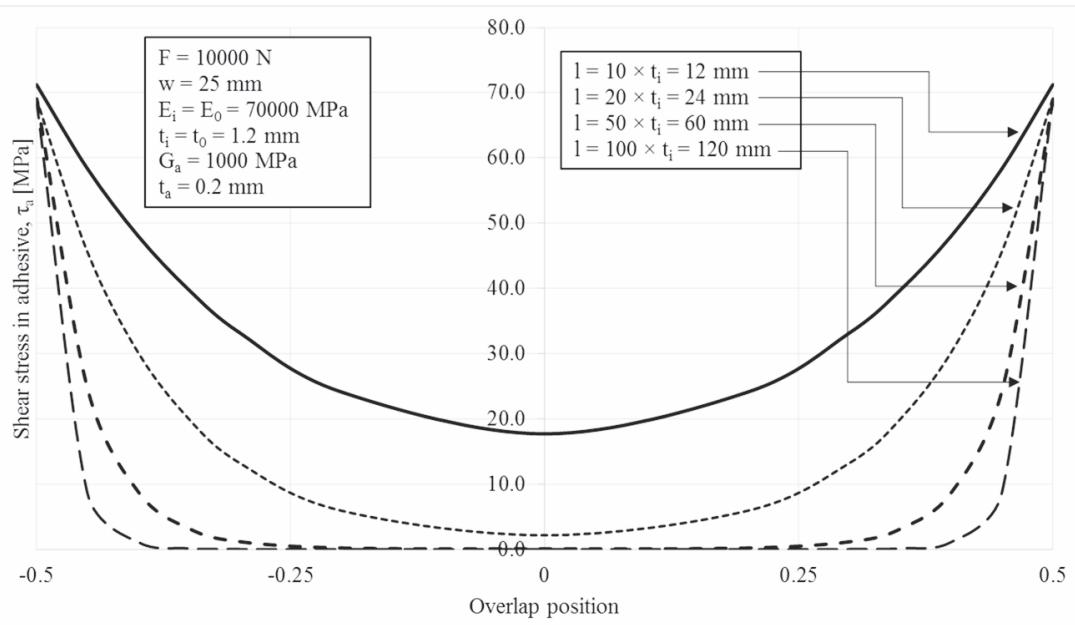

Fig. 12. Elastic adhesive shear stress distribution (Volkerson) for various overlap lengths (normalized). 
As it was shown in Fig. 11 and Fig. 12, shear stress vary along the bondline length. Variation is dependent, among other, on the level of strains in the adherends at any given point, and therefore the only case when shear stress distribution is uniform, is for very stiff adherends. Neverthless, for most of the cases, the strain in the adherends increases from zero at the ends (because load is zero) reaching a maximum at the other end of the joint (adherend carries all the load). These strains adds to displacements caused by the relative movement of the adherends. When the overlap (bondline) length is large enough, the strains in each adherend in the center of the joint will be the same, and the displacement difference will approach zero (for similar adherends). Therefore, shear stress in the adhesive will be equal zero in the center of the joint and maximum at the ends of the joint where the difference in displacements is maximum. As it was shown in Fig. 12 and in Table 1, maximum (peak) shear stress in the adhesive is almost constant for various overlap length, despite the fact that the average shear stress is not. Thus, when sufficient overlap length to enable adhesive shear stress decay to zero in the middle of the joint is achieved, any additional overlap length will not change the load carrying capability of the joint and will only increase the size of the joint.

Table 1. Maximum and average adhesive shear stress values for different overlap length.

\begin{tabular}{|c|c|c|c|}
\hline \multicolumn{2}{|c|}{ Overlap length, $\mathrm{mm}$} & $\tau_{\mathrm{a}_{\mathrm{a}} \max }, \mathrm{MPa}$ & $\tau_{\text {avg, }}, \mathrm{MPa}$ \\
\hline $\mathrm{l}=10 \times \mathrm{ti}=$ & 12 & 71.2 & 33.9 \\
\hline $\mathrm{l}=20 \times \mathrm{ti}=$ & 24 & 69.0 & 17.3 \\
\hline $\mathrm{l}=50 \times \mathrm{ti}=$ & 60 & 69.0 & 7.3 \\
\hline $\mathrm{l}=100 \times \mathrm{ti}=$ & 120 & 69.0 & 4.4 \\
\hline
\end{tabular}

Design of adhesively bonded joint should also take into account the critical environmental conditions. As shown in Fig. 13 and Fig. 14, adhesives materials are highly influenced by temperature and humidity. Environment conditions can affect adhesive strength as well as stiffness. Maximum and minimum service temperatures should always be taken into account $[1,2,15]$.

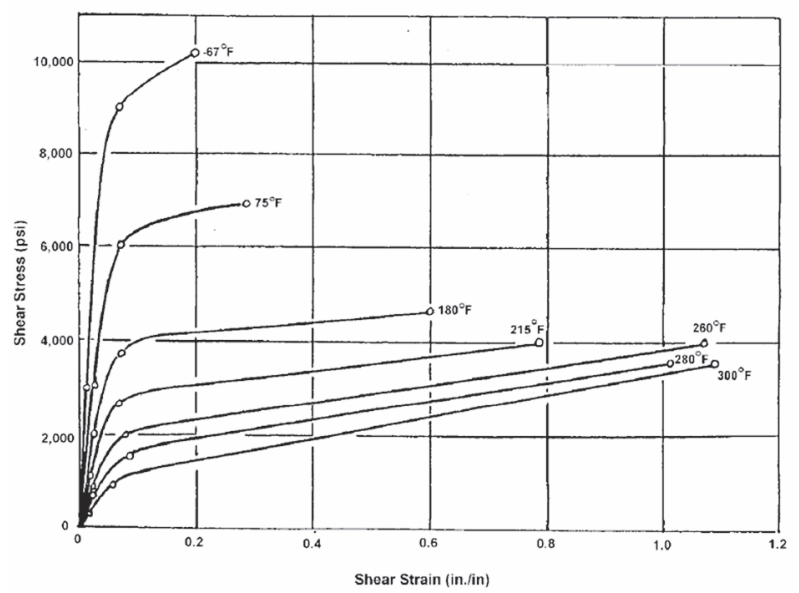

Fig. 13. Shear stress-strain response of FM $300 \mathrm{~K}$ adhesive at different temperatures in ${ }^{\circ} \mathrm{F}[22]$. 


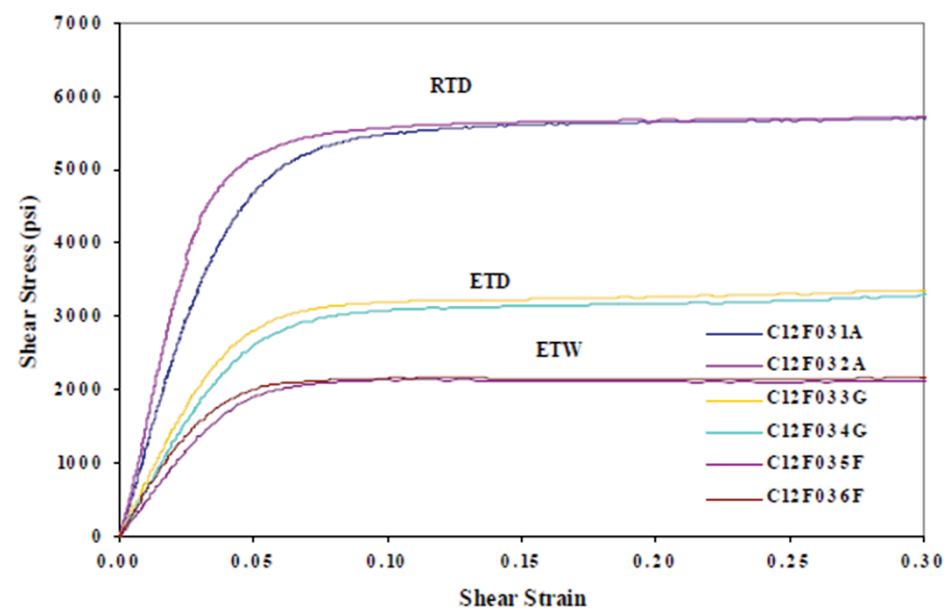

Fig. 14. Example of stress-strain curves with respect to different environmental conditions for EA 9628 film adhesive, bond line $=0.79 \mathrm{~mm}$, ASTM D 5656 thick adherend test method (RTD = Room Temperature Dry, ETD = Elevated Temperature Dry, ETW = Elevated Temperature Wet) [21].

\subsection{Adhesive joint analytical analysis}

Although nowadays FE methods become more and more popular because of their versatility and constantly increasingly computer memory capacity, the analytical solutions, especially closed-form, are still much more efficient. These methods can be classified into two groups depending on solution type: closedformed and numerical. Examples of these solution based on single lap joint will be presented below.

\section{AVERAGE SHEAR STRESS MODEL}

Approach is based on the following main assumptions [23]:

- $\quad$ adherends are rigid;

- $\quad$ adhesive is deformable and is treated as continuous shear spring along overlap;

- $\quad$ constant shear stress $\tau$ along overlap;

- thickness negligence;

- $\quad$ linear-elasticity materials.

In this simple method, the stress distribution is uniform and is given by:

$$
\tau=\frac{F}{A}
$$

where: $F$ - applied force, $A$ - overlap area.

Simplicity of the method causes high popularity in industry application but at the same time is also its main disadvantage. Based on the equation (1), it can be concluded that increasing bonded area $A$ causes reduction of shear stress $\tau$, but in reality it is not the case. The shear stress distribution is nonlinear and in consequences, equation (1) can lead to non-conservative results. For this reason, the method is used with various knock-down factors which take into account shear distribution, environmental conditions, thickness effects and material characteristics. Such approach required extensive testing campaign dedicated to each unique joint type. The stress nonlinearity is caused by difference in adherends 
strain along overlap. Therefore, when the adherends are thick and stiff, the strain difference decreases causing more uniform stress distribution and making the method more reliable.

\section{SHEAR LAG MODEL (VOLKERSEN)}

The theory is based on the following assumptions [24]:

- adhesive is modeled as linear-elastic material and deforms only in shearing;

- adherends are elastic and deforms in tension;

- bending effect caused by eccentric load path for single lap joint is neglected;

- peel stress is neglected;

- stresses are constant across thickness.

The shear stress distribution for single lap joint is given by (2), [15]:

$$
\begin{aligned}
& \tau_{a}(x)=\frac{(F / w) \lambda}{2 \sinh \left(\frac{\lambda l}{2}\right)} \cosh (\lambda x)+\frac{(F / w) \lambda}{2 \cosh \left(\frac{\lambda l}{2}\right)} \sinh (\lambda x)\left[\frac{E_{i} t_{i}-E_{0} t_{0}}{E_{i} t_{i}+E_{0} t_{0}}\right] \\
& \lambda^{2}=\frac{G_{a}}{t_{a}}\left(\frac{1}{E_{i} t_{i}}+\frac{1}{E_{0} t_{0}}\right)
\end{aligned}
$$

where: $F$ - applied force, $w$ - width of the joint, $G_{a}$ - adhesive shear modulus, $w$ - joint width, $E_{0}, E_{i}$ - Young's adherends modulus $t_{i}, t_{0}$ - adherends thickness, $l$-overlap length, $x$ - coordinate along overlap.

Equation (2) provide non-linear stress distribution, an example of which is presented in Fig. 15. In order to take into account adherends shear deformation, the linear shear stress distribution through the adherends thickness has to be assumed. For single lap joint, the correction (3) has to be applied by the replacement $\lambda$ with $\beta$ in equation (2) $[15,25]$. The correction can be essential, for example, in case of single lap joint analysis with composite adherends and thin adhesive. The model was also validated using Digital Image Correlation (DIC) for thick adhesive layer $(-8 \mathrm{~mm})$ and the results showed acceptable accuracy [26].

$$
\beta^{2}=\lambda^{2}\left[1+\frac{G_{a}}{t_{a}}\left(\frac{t_{0}}{3 G_{0}}+\frac{t_{i}}{3 G_{i}}\right)\right]^{-1}
$$

where: $G_{0}, G_{i}-$ Kirchhoff adherends modulus.

\section{SOLUTIONS BASED ON GOLAND AND REISSNER THEORY}

More complex specimen loading, including bending moment and transverse force, was analyzed by Goland and Reissner (G-R) [27]. In comparison to Volkersen's, G-R solution allows to calculate peel stress distribution. It is based on the following assumptions:

- $\quad$ transverse normal and shear strain in the adherends are negligibly small;

- $\quad$ stress is constant across adhesive thickness;

- $\quad$ adhesive layer is infinitely thin.

The stress distribution for balanced single lap joint is given by (4) [23]:

$$
\tau=\frac{\beta_{c}\left(F t_{1}+2 \alpha_{k} M_{k}\right) \cosh \beta_{c} x}{8 \alpha_{a} t_{1} \sinh \beta_{c} c}+\frac{\alpha_{k}\left(F t_{1}-2 M_{k}\right)}{8 \alpha_{a} t_{1} c}
$$




$$
\begin{aligned}
& \sigma=B_{\sigma 1} \sinh \beta_{\sigma} x \sin \beta_{\sigma} x+\beta_{\sigma 4} \cosh \beta_{\sigma} x \cos \beta_{\sigma} x \\
& \beta_{\sigma 1}=\frac{2 \beta_{\sigma}\left[M_{k} \beta_{\sigma}\left(\sinh \beta_{\sigma} c \cos \beta_{\sigma} c+\cosh \beta_{\sigma} c \sin \beta_{\sigma} c\right)+V_{k} \sinh \beta_{\sigma} c \sin \beta_{\sigma} c\right]}{\sinh 2 \beta_{\sigma} c+\sin 2 \beta_{\sigma} c} \\
& \beta_{\sigma 1}=\frac{2 \beta_{\sigma}\left[M_{k} \beta_{\sigma}\left(\sinh \beta_{\sigma} c \cos \beta_{\sigma} c-\cosh \beta_{\sigma} c \sin \beta_{\sigma} c\right)+V_{k} \cosh \beta_{\sigma} c \cos \beta_{\sigma} c\right]}{\sinh 2 \beta_{\sigma} c+\sin 2 \beta_{\sigma} c} \\
& \beta_{c}^{2}=\alpha_{a} \beta_{\tau}^{2} ; \beta_{\tau}=\sqrt{\frac{8 G_{a}}{A_{d 1} t_{a}}} ; \beta_{\sigma}=\frac{\sqrt{2}}{2} \times \sqrt[4]{\frac{2 E_{a}}{D_{1} t_{a}}} ; \alpha_{a}=\frac{1}{4}\left(1+\alpha_{k}\right) ; \alpha_{k}=\frac{4 A_{d 1} t_{1}^{2}}{D_{1}}
\end{aligned}
$$

where: $F$ - applied force, $A_{d 1}$ - extensional stiffness of adherend, $D_{1}$ - bending stiffness of adherend, $E_{a}$ - Young's adhesive modulus, $M_{k}$ - bending moment at the overlap ends, $V_{k}-$ transverse force.

Bending moment and transverse force are related with $F$ by factor $k$ and $k$ 'respectively. Details are presented in [12, 23]. Both models: Volkersen and G-R theory have the following main limitations [12]:

- lack of through-the-thickness stress distribution consideration;

- analysis predicts shear stress on free-surface at the end of the overlap, which does not exist and leads to over conservative analysis results;

- lack of adherends through-the-thickness shear and normal deformations consideration.

In order to overcome these limitations, different expansion of $\mathrm{G}-\mathrm{R}$ solution can be found in literature. For example, the effect of adhesive thickness was considered in [28]. The study of the stress distribution in adhesive joints with dissimilar adherends (different thicknesses and different materials) was presented in [29]. Comparative literature review of adhesive beam model and its analytical solutions can be found in $[12,23,30]$.

Alternative analytical approach is based on stiffness matrix theory for structural analysis of framed structure [31]. The procedure allows to analyze different type of joints in the same manner and it takes into account the following effects:

- the transversal and longitudinal relative displacements along the interface;

- the interaction between the normal and shear stresses;

- the coupling between axial, flexural and shear deformations;

- any transverse load applied on the adherends that fits a second-order polynomial function.

All above mentioned solutions are valid with the following assumption: linear elasticity of adherends and adhesive materials. This methodology can lead to over-conservative analysis results because in case of modern structural adhesives, most of the strain energy up to failure is transmitted through elastis nonlinear behavior. First model which take into account material inelasticity was introduce by Hart-Smith $[18,19]$. Adhesive was modeled as a linear-elastic and perfectly plastic material. Two types of solution of differential equation is used for linear-elastic and non-linear elastic range. In order to obtain adhesive stress distribution considering nonlinearity, the numerical procedures have to be used. Additionally, the theory may take into account balanced and imbalanced adherends stiffness and effect of thermal mismatch between adherends. For some specific conditions, closed-form solution can be obtained.

Besides simple specimen geometry, it is also possible to obtain closed-form solution for more complicated joint geometry with inelastic adhesive character. One of the example is the solution for double-lap joints with stepped outer adherends. The model takes into account adherends shear deformation, thickness variation and it allows for obtaining both shear and peel stress distribution along overlap. Model was validated with corresponding FEM analysis with fine mesh and it allows to obtain excellent agreement [32]. 
All above-mentioned solutions are limited to specimens with relatively simple geometry and loading configuration. In case of complex structures or complex boundary conditions e.g. load variation along structure, described methods cannot be applied and therefore numerical analysis i.e. FEM has to be used.

\subsection{Adhesive joint numerical analysis}

Analysis of adhesive bonding joint is complex and complicated process, even using FE methods where the following issues need to be taken into account:

- $\quad$ occurrence of stress singularity at the ends of the bondline causes high result mesh sizedependency [33];

- $\quad$ obtaining accurate enough result at the end of the overlap where high stress gradient apperars;

- $\quad$ requires using extremely small element size and low aspect ratio close to 1:1 [33];

- $\quad$ adhesive to adherends thickness ratio limits maximal element size [33];

- stress gradients in through the adhesive thickness direction causes requirement of using more than one element along adhesive thickness [33];

- $\quad$ most of the load in adhesive joint is transmitted by plastic strain thus nonlinear material model with plasticity should be used [18].

First four points causes difficulties to pass finite element geometry (mesh) requirements. For example, typical adhesive thickness equal $0.15 \mathrm{~mm}$, result in maximal element dimension equal $0.75 \mathrm{~mm}$ for $5: 1$ element aspect ratio (even if stress gradient through the adhesive thickness is neglected). Such dimension is smaller then practical element size used in engineering strength analysis, especially in case of structural assemblies and / or three dimensional problems. Requirements for relatively small element size for adhesive modeling, causes necessity of preparing local structural models (sub-modeling). Another problem is related with proper selection of criteria based on continuum mechanics to be used in analysis. For a given task two criteria have to be selected: yielding criterion and failure criterion. For yielding, Tresca and von Mises criteria should not be used in case of polymers, because there are no consideration of hydrostatic stress dependency. For adhesives, the yield stress is different for compression/shearing and for tension loading which is caused by crazing effect [34]. This issue can be solved by using the modified DruckerPrager/Cap plasticity model which adequately describes the yield locus for both tensile and compressive hydrostatic stresses [35]. For failure, different criteria can be found in literature e.g.: maximum (shear) stress/strain, maximum von Mises stress, plastic yielding, principal stress/strain $[36,37]$. Irrespective of criterion selection, stress singularity may exist at the joints corners which causes dependency of mesh density and results. In order to overcome this problem, the critical stress or strain value at some distance from the edge can be used to predict the failure. One of such approach is based on Whitney and Nuismer point-stress criterion [38]. It was adapted for analysis of metal-metal adhesive bonding joint. In this approach, the adhesive failure is predicted when shear stress at characteristic length $a_{c b}$, near the overlap corner is equal to shear strength of the adhesive. Methodology allow to determine failure load for different overlap length and adhesive thickness. It requires calibration of the characteristic length $a_{c b}$ in relation to overlap length. Predicted failure load was in good agreement with experiment [39].

Another approach was presented in $[39,40]$ where critical strain was analyzed. The adhesive failure condition is given by (5):

$$
\varepsilon\left(r=r_{c}\right) \geq \varepsilon_{c}
$$

where: $\varepsilon-$ strain, $\varepsilon_{c}-$ critical longitudinal strain, $r_{c}-$ characteristic length.

In this approach, the critical longitudinal strain $\varepsilon_{c}$ is determined by linear analysis of bonded joint with different overlap length (Fig. 15). For complex joint geometry and boundary condition, FEM has to be 
used. Analysis are performed for failure load obtained in experimental tests. The longitudinal strain curves along adhesive mid-plane $\varepsilon(x)$ are plotted against normalized overlap length. Point of curves intersection defines length of critical normalized distance and critical longitudinal strain. In order to calibrate the method, minimum two tests should be performed or, alternatively, mathematical relation can be used. Methodology was verified for both ductile and brittle adhesive and on similar and dissimilar adherends including composite material [39, 40].

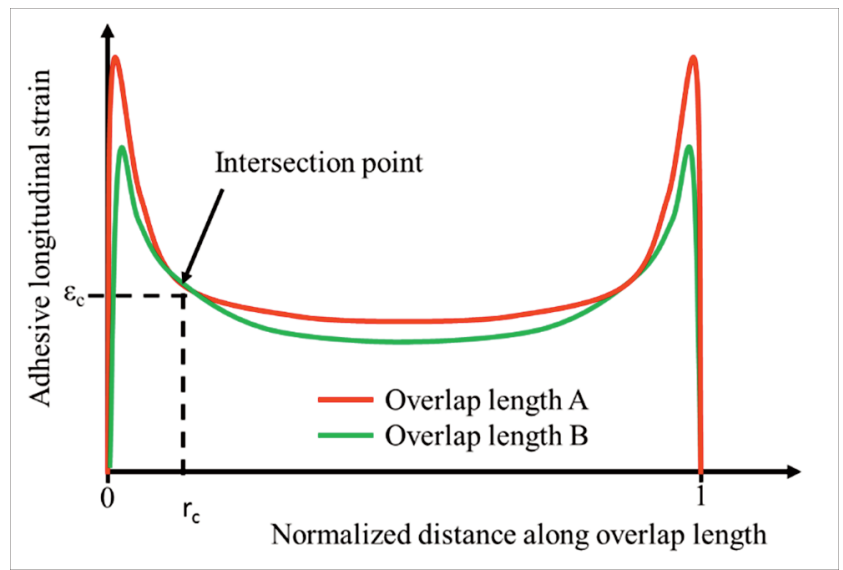

Fig. 15. Longitudinal strain distribution in adhesive mid-plane as a function of normalized distance along overlap length, image prepared based on [41].

\section{COHESIVE ZONE METHOD}

Another approach for adhesive bonding joint analysis is Cohesive Zone Method (CZM), proposed by Barenblatt [42] and Dugdale [43] and described in details in [44]. In this model, two adjacent surfaces (meshes) are bonded together according to nonlinear equation i.e. Traction-Separation Law $\tau(\delta)$ (TSL). Example of TSL for pure loading mode is presented in Fig. 16. For mix-mode loading, two additional criteria are used: stress-based for damage initiation and energetic-based for failure criterion. The singularity issue is solved by application of energetic failure criterion which is based on fracture mechanics. In FEM analysis, this method is realized by application of specially dedicated cohesive or interface elements [44, 45].

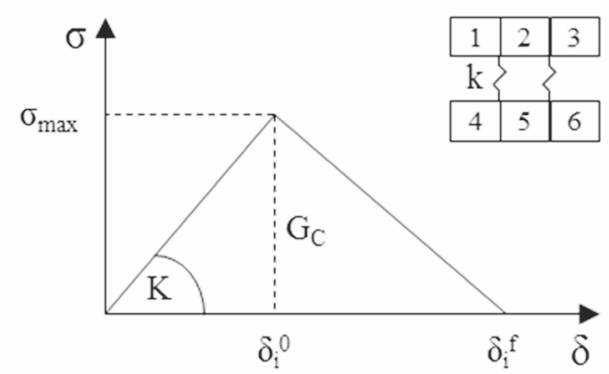

Fig. 16. In Cohezive Zone Model, adjacent surface elements are bonded together by elements which stiffness for pure loading mode are described by Traction-Separation Law $\sigma(\delta)$, e.g. bilinear. 
Cohesive Zone model is defined by given TSL and its parameters. Among different types of TSL, the simplest one is bilinear and it is defined by 3 main parameters: stiffness $K$, maximal stress $\sigma_{\text {max }}$, critical energy release rate $G_{C}$. Referring to adhesive bonding modeling, the most popular types of TSL are: bilinear, exponential and trapezoidal. Literature recommend for brittle adhesive to use bilinear TSL and for ductile adhesive the trapezoidal one [46, 47]. For example, scarf joint with ductile adhesive was modelled using bilinear and user-defined TSL which consist of linear elasticity, plastic hardening and damage softening [49]. In comparison with experiment, bilinear TSL gives underestimated failure load because of lack of adhesive yielding consideration, and therefore more accurate results were obtained for user-defined TSL. For butt-joint, experimental results showed that bilinear TSL is more suitable for brittle adhesive and exponential curve gives more accurate results for ductile adhesive [50]. Although, in majority of literature, possibility of obtaining accurate results are associated with adhesive ductility and TSL selection, there can be some exceptions. Three adhesive types, with different characteristic (from brittle to ductile) were analyzed with bilinear, exponential and trapezoidal TSL [51]. All three types of TSL predict similar results and all were accurate in comparison with experimental tests for different adhesives.

Not all TSL parameters can be directly determined by experimental tests. Critical Energy Release Rate $\mathrm{G}_{\mathrm{C}}$ in mode I, II or mix mode are determined according to well-known specimen configuration: e.g. mode I - Double Cantilever Beam (DCB) [52], mode II - End Notched Flexure (ENF) and mixmode I/II - Mixed-Mode Bend test specimen (MMB) [23]. For mode II and mix-mode, right now, there is not available any standard test method dedicated to adhesive materials. In order to determine fracture toughness for adhesive materials, similar specimen configuration as for composite materials for which standards exists can be adapted (mode II [53] and mix-mode [54]). For determination of maximal stress $\sigma_{\text {max }}$, and stiffness $K$ of elastic response there is also lack of available standards. In order to define these parameters the following methods can be used:

- Property determination method, in which bulk adhesive properties are used in order to evaluate the maximal stress $\sigma_{\max }$ and stiffness $K$ [47].

- Inverse method, in which CZM parameters are calibrated by iterative comparison of experimental results and numerical analysis with different parameters values. Initial parameters values can be assumed based on adhesive bulk properties [47].

- Direct method, in which the whole TSL curve is determined. In this approach, experimentally determined curve, $J$ integral in function of cohesive zone displacement $\delta_{i}$, is differentiated according to (6) [55].

$$
\frac{\delta J}{\delta \delta_{i}}=\sigma_{i}\left(\delta_{i}\right)
$$

Although in literature it is common to find many examples of accurate CZM results, most of them are dedicated to relatively simple specimen geometry e.g.: single lap joint [48], scarf joint [51]. The reason behind it can be method requirement of using small size of cohesive element e.g. in 3D single lap joint analysis $(240 \mathrm{~mm} \times 15 \mathrm{~mm} \times 2.4 \mathrm{~mm})$, the adherends were modeled using 75000 elements, while the $10 \mathrm{~mm}$ long adhesive was modeled with 3750 elements.

\section{CONCLUSIONS}

Among many different aspects of adhesive bonding, engineers have to primarily reconcile two: designing reliable structure for required margin of safety and minimizing structural mass. Presented methods differ from each other with regards to degree of complexity. First one, average stress method, is currently the easiest and the most general one. Due to its simplicity and very inaccurate analysis results, 
design values for adhesive shear stress has to be set on a very low level e.g. $8 \%$ of bond lap-shear strength (41.4 versus $3.4 \mathrm{MPa}$ ) [56]. It can lead to over conservative results and may result in having mechanical joint being more weight efficient than adhesively bonded joint. From the engineering point of view, with experimentally confirmed design values, method is easy to implement and use. In order to design reliable and lighter structure, more complex analytical methods with nonlinear relation along overlap may be used: Volkersen solution [24] or Hart-Smith solution considering adhesive ductility [18, 19]. Although mentioned methods are fast and simple, solutions are limited to simple structural configuration like single or double lap joint and typical boundary condition. In case of complex structure, which is the case in most of the practical engineering problems, numerical analysis has to be used. Currently two methods are being developed: first based on point-stress criterion and second based on Cohesive Zone model. Both of them require experimental calibration and none of them were not experimentally validated at complex engineering case level. From practical engineering point of view, in FEM analysis, it is desired to use possibly large element size and therefore, comparing this two methods, the point stress/strain method seems to be more suitable for this purpose. CZM can be more general and may give more accurate results, but unfortunately has also essential drawbacks. It is complicated to use, analysis are time consuming because of difficulties with achieving convergences, and it requires additional experimental tests which are not always standardized.

\section{REFERENCES}

[1] Baker, A. A., and Scott, M. L., eds., 2016, Composite Materials for Aircraft Structures, AIAA/American Institute of Aeronautics and Astronautics, Inc, Reston, Virginia.

[2] Heslehurst, R. B., 2013, Design and Analysis of Structural Joints with Composite Materials, DEStech Publ, Lancaster, Pa.

[3] Kim, H., and Kedward, K., 2001, Stress Analysis Of In-Plane, Shear-Loaded, Adhesively Bonded Composite Joints And Assemblies, DOT/FAA/AR-01/7, FAA.

[4] Baron, A., 2012, The I-23 "Manager" passenger plane. Selected research problems (in Polish). Scientific Publication of the Institute of Aviation, Warsaw.

[5] Speth, D. R., Yang, Y. P., and Ritter, G. W., 2010, "Qualification of Adhesives for Marine Composite-to-Steel Applications,” Int. J. Adhes. Adhes., 30(2), pp. 55-62.

10.1016/j.ijadhadh.2009.08.004.

[6] Wahab, M. A., 2014, The Mechanics of Adhesives in Composite and Metal Joints: Finite Element Analysis with ANSYS, DEStech Publications, Lancaster, PA.

[7] Pegoretti, A., ed., 2019, Adhesive Joining of Structural Components: New Insights and Technologies, SAE International, Warrendale, Pennsylvania, USA.

[8] Banea, M. D., and da Silva, L. F. M., 2009, "Adhesively Bonded Joints in Composite Materials: An Overview,” Proc. Inst. Mech. Eng. Part J. Mater. Des. Appl., 223(1), pp. 1-18.

10.1243/14644207JMDA219.

[9] Da Silva, L. F. M., 2018, Handbook of Adhesion Technology, Springer Science+Business Media, LLC, New York, NY.

[10] Gleich, D. M., 2002, Stress Analysis of Structural Bonded Joints, DUP Science, Delft.

[11] Zhu, Y., and Kedward, K., 2005, Methods of Analysis and Failure Predictions for Adhesively Bonded Joints of Uniform and Variable Bondline Thickness, DOT/FAA/AR 05-12, FAA.

[12] da Silva, L. F. M., das Neves, P. J. C., Adams, R. D., and Spelt, J. K., 2009, "Analytical Models of Adhesively Bonded Joints — Part I: Literature Survey,” Int. J. Adhes. Adhes., 29(3), pp. 319-330. 10.1016/j.ijadhadh.2008.06.005.

[13] He, X., 2011, “A Review of Finite Element Analysis of Adhesively Bonded Joints,” Int. J. Adhes. Adhes. 
[14] 2011, A Space Engineering Adhesive Boding Handbook, ECSS-E-HB-32-21, ESA Requirements and Standards Division, Netherlands.

[15] Esp, B., 2017, Practical Analysis of Aircraft Composites, Grand Oak Publishing.

[16] Flinn, B., and Phariss, M., 2006, The Effect of Peel-Ply Surface Preparation Variables on Bond Quality, DOT/FAA/AR-06/28, FAA.

[17] Potter, D. L., 1979, Primary Adhesively Bonded Structure Technology (PABST): Design Handbook for Adhesive Bonding, AFFDL-TR-79-3129, Air Force Flight Development Laboratory, Long Beach.

[18] Hart-Smith, L. J., 1973, Adhesive Bonded Single Lap Joints, NASA-CR-112236, NASA, USA.

[19] Hart-Smith, L. J., 1973, Adhesive Bonded Double-Lap Joints, NASA-CR-112235, NASA, USA.

[20] Tomblin, J., Strole, K., Dodosh, G., and Ilcewicz, L., 2005, Assessment of Industry Practices for Aircraft Bonded Joints and Structures, DOT/FAA/AR-05/13, FAA.

[21] Tomblin, J., Seneviratne, W., Escobar, P., and Yoon-Khian, Y., 2002, Shear Stress-Strain Data for Structural Adhesives, DOT/FAA/AR-02/97, FAA.

[22] 2012, "CMH-17-1G (Volume 1 of 6) Composite Materials Handbook: Polymer Matrix Composites Guidelines for Characterization of Structural Materials."

[23] Tong, L., and Luo, Q., 2018, "Analytical Approach," Handbook of Adhesion Technology, L.F.M. da Silva, A. Öchsner, and R.D. Adams, eds., Springer International Publishing, Cham, pp. 665-700.

[24] Volkersen, O., 1938, "Die Nietkraftverteilung in Zugbeanspruchten Nietverbindungen Mit Konstanten Laschenquerschnitten,” Luftfahrtforschung, 15, pp. 41-47.

[25] Tsai, M. Y., Oplinger, D. W., and Morton, J., 1998, "Improved Theoretical Solutions for Adhesive Lap Joints,” Int. J. Solids Struct., 35(12), pp. 1163-1185.

[26] Saleh, M. N., Saeedifar, M., Zarouchas, D., and De Freitas, S. T., 2020, "Stress Analysis of DoubleLap Bi-Material Joints Bonded with Thick Adhesive,” Int. J. Adhes. Adhes, 97, p. 102480. 10.1016/j.ijadhadh.2019.102480.

[27] Goland, M., and Reissner, E., 1944, “Stresses in Cemented Joints,” J. Appl. Mech., 11, pp. 4-47.

[28] Wang, J., 2013, "Mechanics and Fracture of Hybrid Material Interface Bond," PhD, The University of Akron.

[29] Zhao, B., Lu, Z.-H., and Lu, Y.-N., 2011, “Closed-Form Solutions for Elastic Stress-Strain Analysis in Unbalanced Adhesive Single-Lap Joints Considering Adherend Deformations and Bond Thickness," Int. J. Adhes. Adhes., 31(6), pp. 434-445. 10.1016/j.ijadhadh.2011.03.002.

[30] da Silva, L. F. M., das Neves, P. J. C., Adams, R. D., Wang, A., and Spelt, J. K., 2009, "Analytical Models of Adhesively Bonded Joints-Part II: Comparative Study,” Int. J. Adhes. Adhes., 29(3), pp. 331-341. 10.1016/j.ijadhadh.2008.06.007.

[31] Areiza-Hurtado, M., Vega-Posada, C. A., and Aristizabal-Ochoa, J. D., 2019, "A Novel Linear Matrix Method to Analyze Adhesive Joints," Compos. Struct., 226, p. 111193. 10.1016/j.compstruct.2019.111193.

[32] Wang, S., Xie, Z., and Li, X., 2019, "A Modified Analytical Model for Stress Analysis of Adhesively Bonded Stepped-Lap Joints under Tensile Load,” Eur. J. Mech. A/Solids, 77, p. 103794. 10.1016/j.euromechsol.2019.103794.

[33] Society of Automotive Engineers, and National Institute for Aviation Research (U.S.), eds., 2012, Composite Materials Handbook Volume 3, SAE International on behalf of CMH-17, a division of Wichita State University, Warrendale, Pa.

[34] García, J. A., Chiminelli, A., García, B., Lizaranzu, M., and Jiménez, M. A., 2011, "Characterization and Material Model Definition of Toughened Adhesives for Finite Element Analysis,” Int. J. Adhes. Adhes., 31(4), pp. 182-192. 10.1016/j.ijadhadh.2010.12.006.

[35] Wang, C. H., and Chalkley, P., 2000, "Plastic Yielding of a Film Adhesive under Multiaxial Stresses," Int. J. Adhes. Adhes., 20(2), pp. 155-164. 10.1016/S0143-7496(99)00033-0. 
[36] Rodríguez, R. Quispe, Paiva, W. P. de, Sollero, P., Rodrigues, M. R. Bertoni, and Albuquerque, É. L. de, 2012, “Failure Criteria for Adhesively Bonded Joints," Int. J. Adhes. Adhes., 37, pp. 2636. 10.1016/j.ijadhadh.2012.01.009.

[37] Campilho, R. D. S. G., ed., 2017, Strength Prediction of Adhesively-Bonded Joints, CRC Press, Taylor \& Francis Group, CRC Press is an imprint of the Taylor \& Francis Group, an informa business, Boca Raton.

[38] Whitney, J. M., and Nuismer, R. J., 1974, "Stress Fracture Criteria for Laminated Composites Containing Stress Concentrations,” J. Compos. Mater., 8(3), pp. 253-265.

$10.1177 / 002199837400800303$.

[39] Sajikumar, K. S., Kumar, N. A., and Rao, B. N., 2014, "Application of the Point Stress Criterion to Assess the Bond Strength of a Single-Lap Joint," Strength Mater., 46(4), pp. 518-525. 10.1007/s11223-014-9577-z.

[40] Akhavan-Safar, A., Silva, L. F. M. da, and Ayatollahi, M. R., 2017, "An Investigation on the Strength of Single Lap Adhesive Joints with a Wide Range of Materials and Dimensions Using a Critical Distance Approach,” Int. J. Adhes. Adhes., 78, pp. 248-255.

10.1016/j.ijadhadh.2017.08.009.

[41] Cruz-G, C. E., Akhavan-Safar, A., da Silva, L. F. M., and Ayatollahi, M. R., 2020, "On the Evaluation of a Critical Distance Approach for Failure Load Prediction of Adhesively Bonded Dissimilar Materials," Continuum Mech. Thermodyn. 32, 1647-1657. 10.1007/s00161-020-00871-7.

[42] Barenblatt, G. I., 1962, "The Mathematical Theory of Equilibrium Cracks in Brittle Fracture," Advances in Applied Mechanics, H.L. Dryden, T. von Kármán, G. Kuerti, F.H. van den Dungen, and L. Howarth, eds., Elsevier, pp. 55-129.

[43] Dugdale, D. S., 1960, "Yielding of Steel Sheets Containing Slits," J. Mech. Phys. Solids, 8(2), pp. 100-104. 10.1016/0022-5096(60)90013-2.

[44] Camanho, P. P., and Davila, C. G., 2002, Mixed-Mode Decohesion Finite Elements for the Simulation of Delamination in Composite Materials, NASA/TM-2002-211737, NASA Langley Research Center; Hampton, VA, United States.

[45] “Abaqus Analysis User's Manual - Dokumentacja Programu Abaqus 6.12.”

[46] 2016, "MSC Nastran 2016, Nonlinear User's Guide, SOL400."

[47] da Silva, L. F. M., and Campilho, R. D. S. G., 2012, "Advances in Numerical Modelling of Adhesive Joints," Advances in Numerical Modeling of Adhesive Joints, L.F.M. da Silva, and R.D.S.G. Campilho, eds., Springer Berlin Heidelberg, Berlin, Heidelberg, pp. 1-93.

[48] Carvalho, U. T. F., and Campilho, R. D. S. G., 2017, "Validation of Pure Tensile and Shear Cohesive Laws Obtained by the Direct Method with Single-Lap Joints," Int. J. Adhes. Adhes., 77, pp. 41-50. 10.1016/j.ijadhadh.2017.04.002.

[49] Sun, L., Tie, Y., Hou, Y., Lu, X., and Li, C., 2020, "Prediction of Failure Behavior of Adhesively Bonded CFRP Scarf Joints Using a Cohesive Zone Model,” Eng. Fract. Mech., 228, p. 106897. 10.1016/j.engfracmech.2020.106897.

[50] Zhang, J., Wang, J., Yuan, Z., and Jia, H., 2018, "Effect of the Cohesive Law Shape on the Modelling of Adhesive Joints Bonded with Brittle and Ductile Adhesives," Int. J. Adhes. Adhes., 85, pp. 37-43. 10.1016/j.ijadhadh.2018.05.017.

[51] Silva, D. F. O., Campilho, R. D. S. G., Silva, F. J. G., and Carvalho, U. T. F., 2018, "Application a Direct/Cohesive Zone Method for the Evaluation of Scarf Adhesive Joints," Appl. Adhes. Sci., 6(1), p. 13. 10.1186/s40563-018-0115-2.

[52] 2009, "ISO 25217:2009, Adhesives - Determination of the Mode 1 Adhesive Fracture Energy of Structural Adhesive Joints Using Double Cantilever Beam and Tapered Double Cantilever Beam Specimens." 
[53] D30 Committee, ASTM D5041-98(2019), Test Method for Determination of the Mode II Interlaminar Fracture Toughness of Unidirectional Fiber-Reinforced Polymer Matrix Composites, ASTM International.

[54] D30 Committee, ASTM D6671 / D6671M-19, Test Method for Mixed Mode I-Mode II Interlaminar Fracture Toughness of Unidirectional Fiber Reinforced Polymer Matrix Composites, ASTM International.

[55] Sørensen, B. F., and Jacobsen, T. K., 2003, "Determination of Cohesive Laws by the J Integral Approach,” Cohesive Models, 70(14), pp. 1841-1858. 10.1016/S0013-7944(03)00127-9.

[56] Davis, M., and Tomblin, J., 2007, "DOT/FAA/AR-TN06/57, Best Practice in Adhesive-Bonded Structures and Repairs."

\title{
PROJEKTOWANIE ORAZ METODY OBLICZEŃ KOMPOZYTOWYCH POŁĄCZEŃ KLEJONYCH
}

\begin{abstract}
Abstrakt
W artykule przedstawione zostały wyniki przeglądu literatury poświęconemu metodom projektowania oraz analiz wytrzymałościowych kompozytowych połączeń klejonych. Wybrane oraz opisane zostały metody, które mogą posłużyć jako podstawa do opracowania praktycznej inżynierskiej metodologii projektowania połączeń klejonych. Zaczynając od prostych oraz szybkich metod analitycznych: metoda średniego naprężenia tnącego, shear lag model, klejowy model belkowy, poprzez bardziej skomplikowane i czasochłonne metody numeryczne wspierane przez metodę elementów skończonych: modele globalne, modele lokalne, model strefy kohezyjnej. Omówiono założenia oraz odpowiedniość każdej z metod. Proste oraz szybkie metody, aby były niezawodne, muszą zawierać wiele założeń które prowadzą do przewymiarowania struktury. W celu optymalizacji struktury oraz redukcji jej masy, bardziej złożone i czasochłonne metody musą zostać użyte. W związku z tym, wybór odpowiedniej metody do danego zagadnienia powinien być zawsze zrównoważony pomiędzy wytrzymałością, trwałością, kosztem oraz masą.
\end{abstract}

Słowa kluczowe: kompozyty, kleje, metody analityczne, metody numeryczne, obliczenia wytrzymałościowe. 